\title{
Endoplasmic reticulum stress mediates house dust mite-induced airway epithelial apoptosis and fibrosis
}

Sidra M Hoffman ${ }^{1}$, Jane E Tully ${ }^{1}$, James D Nolin ${ }^{1}$, Karolyn G Lahue ${ }^{1}$, Dylan H Goldman ${ }^{1}$, Nirav Daphtary², Minara Aliyeva², Charles G Irvin², Anne E Dixon², Matthew E Poynter ${ }^{2}$ and Vikas Anathy ${ }^{1 *}$

\begin{abstract}
Background: The endoplasmic reticulum (ER) stress response participates in many chronic inflammatory and autoimmune diseases. In the current study, we sought to examine the contribution of ER stress transducers in the pathogenesis of three principal facets of allergic asthma: inflammation, airway fibrosis, and airways hyperresponsiveness.

Methods: House Dust Mite (HDM) was used as an allergen for in vitro and in vivo challenge of primary human and murine airway epithelial cells. ER stress transducers were modulated using specific small interfering RNAs (siRNAs) in vivo. Inflammation, airway remodeling, and hyperresponsiveness were measured by total bronchoalveolar lavage (BAL) cell counts, determination of collagen, and methacholine responsiveness in mice, respectively.

Results: Challenge of human bronchiolar and nasal epithelial cells with HDM extract induced the ER stress transducer, activating transcription factor 6 a (ATF6a) as well as protein disulfide isomerase, ERp57, in association with activation of caspase-3. SiRNA-mediated knockdown of ATF6a and ERp57 during HDM administration in mice resulted in a decrease in components of HDM-induced ER stress, disulfide mediated oligomerization of Bak, and activation of caspase-3. Furthermore, siRNA-mediated knockdown of ATF6a and ERp57 led to decreased inflammation, airway hyperresponsiveness and airway fibrosis.

Conclusion: Collectively, our work indicates that HDM induces ER stress in airway epithelial cells and that ATF6a and ERp57 play a significant role in the development of cardinal features of allergic airways disease. Inhibition of ER stress responses may provide a potential therapeutic avenue in chronic asthma and sub-epithelial fibrosis associated with loss of lung function.
\end{abstract}

Keywords: Allergen, HDM, Unfolded protein response, ER stress, Apoptosis, Asthma, Airway fibrosis

\section{Background}

Airway inflammation and fibrosis impact lung structure and function in allergic asthma [1]. For instance, chronic asthmatics display extensive airway remodeling characterized by sub-epithelial fibrosis, goblet cell hyperplasia and increased thickness of the basement membrane [2-4]. To date, the processes that facilitate airway fibrosis in allergic asthma remain poorly understood and require a deeper understanding of the cellular and molecular responses

\footnotetext{
* Correspondence: vikas.anathy@med.uvm.edu

'Department of Pathology, Vermont Lung Center University of Vermont College of Medicine, Burlington, VT 05405, USA

Full list of author information is available at the end of the article
}

to allergens in order to identify potential therapeutic targets.

House Dust Mite (HDM) is one of the most commonly found airborne allergens [5], inducing an allergic response in $50-85 \%$ of asthmatics $[5,6]$. Extracts of HDM contain fungal spores, chitin, fecal pellets (containing proteases), Dermatophagoide (Der) family of proteins and lipopolysaccharide (LPS) [7-10]. Studies in rodents have shown that these components can activate multiple receptors present on airway epithelial cells, inducing the secretion of growth factors, the production of cytokines that regulate subsequent activation of $\mathrm{T}$ cells, mucus metaplasia,
C Biomed Central 
inflammation, airways hyperresponsiveness (AHR), and fibrosis $[5,11,12]$.

Physiological demand for increases in protein folding can create an imbalance in synthesis and capacity to fold. This leads to an increase in misfolded proteins in the endoplasmic reticulum (ER), initiating the ER stress response [13]. In mammalian cells, misfolded proteins are sensed by three ER transmembrane proteins: Inositol Requiring Enzyme 1 (IRE1), activating transcription factor 6 (ATF6), and PKR-like ER kinase (PERK) [14]. A prolonged unfolded protein response (UPR) can cause CCAAT/enhancer-binding protein (C/EBP) homologous protein (CHOP)-induced apoptosis [13]. Additionally, to cope with excessive protein folding load, the protein disulfide isomerases (PDIs), which construct disulfide bridges (-S-S-) in the ER, are upregulated [15]. One such PDI, ERp57, mediates misfolded protein-induced apoptosis by oligomerization of Bak through the formation of inter-molecular disulfide (-S-S-) bridges and the permeabilization of mitochondria [16]. Studies thus far have investigated ER stress-dependent IRE1 signaling during mucus metaplasia in ovalbumin-induced allergic airway disease $[17,18]$. ER stress is known to play a prominent role in apoptosis of alveolar type II epithelial cells in Idiopathic Pulmonary Fibrosis (IPF) $[19,20]$ and Hermansky Pudlak Syndrome (HPS) [21]. It remains unknown whether ER stress responses are triggered by human asthma relevant allergens such as HDM. Furthermore, it is not clear whether allergen-induced airway epithelial ER stress and apoptosis are linked to sub-epithelial fibrosis and impairment in respiratory mechanics in a murine model of allergic airway disease.

The goal of the present study was to evaluate the impact of HDM, an asthma-relevant allergen, on ER stress responses, apoptosis in airway epithelial cells and subsequent effects on fibrosis and lung function. Our results demonstrate enhanced expression of ER stress transducers in murine and human epithelial cells in response to HDM challenge. In mice, airway epithelial ER stress was associated with up regulation of apoptotic and fibrotic markers after HDM exposure. In vivo siRNA mediated knockdown of ATF6 $\alpha$ and ERp57 attenuated inflammation and AHR, and abrogated airway fibrosis. These results indicate a critical role of airway epithelial ER stress in allergen-induced airway inflammation and fibrosis.

\section{Materials and methods}

\section{Cell culture, siRNA transfection and caspase-3 assay}

A human bronchial epithelial cell line (HBE) was kindly provided by Dr. Albert van der Vliet-University of Vermont, and cultured as described previously [22,23] and primary human nasal epithelial cells were cultured as described previously [24]. Human cell lines were exposed to either PBS or $25 \mu \mathrm{g} / \mathrm{ml}$ of HDM (Greer, Lenoir, NC). All protocols that utilize primary human nasal epithelial cells were approved by the University of Vermont Institutional Review Board. Cells were transfected with plasmids or siRNA as described [25,26]. Caspase-3 activities were measured using Caspase-Glo 3 (Promega, Madison, WI) reagents, according to the manufacturer's protocol (Promega, Madison, WI). Results were expressed in Relative Luminescence Units (RLU), after subtraction of background luminescence values. Cell death was measured by MTT assay [25]. All results were obtained from 3 independent experiments conducted in triplicate.

\section{HDM and OVA-LPS models of allergic airway disease}

For all experiments, 8 to 12 wk old WT BALB/c mice (Jackson Laboratories) were used, as approved by the Institutional Animal Care and Use Committee. Mice ( $\mathrm{n}=10$ /group) were anesthetized with isofluorane and exposed to $50 \mu \mathrm{g}$ of the allergen, HDM (GREER-containing 35 endotoxin units/mg) extract, resuspended in PBS, via intranasal administration on day 0 and boosted again on day 7. Mice were then administered $50 \mu \mathrm{g}$ of HDM consecutively on days $14-18$, and euthanized 48 h post final exposure. The control group was given $50 \mu \mathrm{l}$ of sterile PBS alone at all time points. Alternatively, mice were sensitized via oropharyngeal administration of $100 \mu \mathrm{g}$ of low endotoxin Ovalbumin (Grade V, Sigma Aldrich) in PBS with $0.1 \mu \mathrm{g}$ of LPS on days 0 and 7, challenged using 6 doses of aerosolized 1\% OVA in PBS for $30 \mathrm{~min}$ on days 14-19, and euthanized on day 21 . This protocol was adapted from a previously described method of airway sensitization and challenge [27].

\section{SiRNA administration of ERp57 and ATF6a}

Mice ( $\mathrm{n}=10$ /group) were anesthetized with isofluorane and administered $10 \mathrm{mg} / \mathrm{kg}$ of scrambled small interfering (si) RNA or siRNA for ERp57 (Thermo Scientific-L45187) and ATF6 $\alpha$ (ORIGENE-SR418766) oropharyngeally on days $-1,6$, and 13 , and again on days 16 and 19X. Simultaneously, mice were exposed to $50 \mu \mathrm{g}$ of HDM resuspended in PBS, or PBS alone via intranasal administration on days 1 and 7. Mice were then administered $50 \mu \mathrm{g}$ of HDM consecutively, on days 14-18 and euthanized $72 \mathrm{~h}$ following the final HDM exposure. On day 16, when siRNA administration coincided with HDM exposure, mice received siRNA $6 \mathrm{~h}$ prior to intranasal administration of HDM.

\section{Assessment of AHR}

Mice ( $n=10$ /group) were anesthetized with an intraperitoneal injection of pentobarbital sodium $(90 \mathrm{mg} / \mathrm{kg})$, tracheotomized using an 18 gauge cannula, then mechanically ventilated at 200 breaths/min using a FlexiVent ${ }^{\mathrm{Tm}}$ computer controlled small animal ventilator (SCIREQ). While on the 
ventilator mice also received the paralytic, pancuronium bromide. The parameters Newtonian resistance (Rn), tissue damping $(\mathrm{G})$, and elastance $(\mathrm{H})$ were calculated as previously described $[28,29]$. Airway responsiveness is represented as the average of the 3 peak measurements for each animal, obtained at incremental methacholine doses.

\section{Bronchoalveolar lavage processing}

Bronchoalveolar lavage (BAL) from mice ( $n=10$ /group) was collected. Total and differential cell counts were performed as previously described [20]. Briefly, cells were isolated by centrifugation and total cell counts were enumerated using the Advia 120 automated hematology analyzer system. Differential cell counts were obtained via cytospins using Hema3 stain reagents (Fisher Scientific). Differentials were performed on a minimum of 300 cells per animal.

\section{Western blot analysis}

Following dissection, right lung lobes were flash frozen for protein analysis. Lungs were pulverized, and lysed in buffer containing $137 \mathrm{mM}$ Tris. $\mathrm{HCl}$ ( $\mathrm{pH}$ 8.0), $130 \mathrm{mM}$ $\mathrm{NaCl}$, and 1\% NP-40. Proteins from cell lysates were prepared in the same buffer. Insoluble proteins were pelleted via centrifugation, and following protein quantitation of the supernatant, samples were resuspended in loading buffer with dithiothrietol (DTT), and resolved by SDS-PAGE. Proteins were transferred to PVDF and membranes were probed using a standard immunoblotting protocol using the following primary antibodies: P-IRE, IRE, GRP78, ATF6 $^{50}$ and CHOP (Abcam), ERp57, GRP94 (Stressgen), Poly (ADP-ribose) polymerase (PARP) (BD Pharmingen) and $\beta$-actin (Sigma).

\section{Non reducing gel electrophoresis}

Lung homogenates were resuspended in loading buffer without the reducing agent dithiothrietol (DTT). A separate set of samples were resuspended in loading buffer with DTT to reduce the disulfide bonds. The samples were resolved by SDS-PAGE and subjected to western blot analysis.

\section{Immunofluorescence}

Following euthanization, left lobes were fixed with $4 \%$ paraformaldehyde, stored at $4^{\circ} \mathrm{C}$ overnight for fixation of the tissue, mounted in paraffin, and $5 \mu \mathrm{m}$ sections were affixed to glass microscope slides for histopathology as previously described [30]. Sections were prepared for immunofluorescence by deparaffinizing with xylene and rehydrating through a series of ethanols [30]. For antigen retrieval, slides were heated for $20 \mathrm{~min}$ in $95^{\circ} \mathrm{C}$ citrate buffer $(\mathrm{pH}$ 6.0) with $0.05 \%$ TWEEN-20 then rinsed in distilled water. Sections were then blocked for $1 \mathrm{~h}$ in $1 \%$ bovine serum albumin (BSA) in PBS, followed by incubation with primary antibody for ERp57 (Stressgen), and Caspase-3 (Cell Signal) at 1:500, overnight at $4^{\circ} \mathrm{C}$. Slides were then washed $3 \times 5 \mathrm{~min}$ in PBS, incubated with Alexafluor 647 at 1:1000 in 1\% BSA, and counterstained with DAPI in PBS at 1:4000 for nuclear localization. Sections were imaged using a Zeiss 510-META confocal laser scanning microscope.

\section{Measurement of collagen and immunohistochemistry}

Collagen content was measured via the Sircol assay $(n=10 /$ group) (Biocolor Ltd, UK). Briefly, lung lobes were diced and placed in $500 \mu \mathrm{l}$ of $10 \mathrm{mg} / \mathrm{mL}$ pepsin in $0.5 \mathrm{M}$ acetic acid for $3 \mathrm{~h}$ at $37^{\circ} \mathrm{C}$, or until lungs were completely digested. The digest was spun at $10,000 \mathrm{~g}$ for $10 \mathrm{~min}$ at room temperature. Fifty microliters of the supernatant was mixed vigorously with $500 \mu \mathrm{L}$ of sircol dye solution for $30 \mathrm{~min}$ and then spun again at 10,000 $\mathrm{g}$ for $10 \mathrm{~min}$. Excess dye was decanted off, and the resulting pellet was dissolved in $500 \mu \mathrm{L}$ of an alkaline solution, $200 \mu \mathrm{L}$ of which was pipetted in duplicates into a 96 well plate and measured at $540 \mathrm{~nm}$. To evaluate regional changes in alpha-smooth muscle actin ( $\alpha \mathrm{SMA})$, fixed sections were prepared for immunostaining by deparaffinizing with xylene and rehydrating through a series of ethanols. For antigen retrieval, slides were heated for $20 \mathrm{~min}$ in $95^{\circ} \mathrm{C}$ citrate buffer ( $\mathrm{pH}$ 6.0), then rinsed in distilled water. Sections were then blocked for $1 \mathrm{~h}$ in blocking serum as per manufacturer's instructions (Vectastain Alkaline Phosphatase Universal, Vector). Slides were then washed in TBS with $0.1 \%$ TWEEN-20 $3 \times 5 \mathrm{~min}$, followed by incubation with primary antibody for $\alpha$ SMA (Sigma) overnight at $4{ }^{\circ} \mathrm{C}$. Sections were washed again and incubated with a biotinylated universal secondary antibody (Vectastain Alkaline Phosphatase Universal, Vector) for $30 \mathrm{~min}$ at room temperature. Slides were washed and incubated with the Vectastain ABC-AP reagent (prepared as per manufacturer's instructions) for $30 \mathrm{~min}$ at room temperature. Sections were then incubated with Vector Red Alkaline Phosphatase Substrate Kit I (Vector) for $10 \mathrm{~min}$ at room temperature, rinsed with tap water, and counterstained with Mayer's Hemotoxylin.

\section{Statistics}

All assays were performed in triplicates. Data were analyzed by one-way analysis of variance (ANOVA) using the Tukey's test to adjust for multiple comparisons or student's $\mathrm{t}$ test where appropriate. Histopathological scores were analyzed using the Kruskal-Wallis test and Dunn's multiple comparison post hoc tests. Data from multiple experiments were averaged and expressed as mean values \pm SEM. 


\section{Results}

HDM induces ER stress and death in human epithelial cells

HDM is a complex allergen known to activate multiple receptors and their consequent downstream pathways [5]. In the current study, we hypothesized that these events would result in increased ER stress in epithelial cells. To address this hypothesis, primary human nasal epithelial (PHNE) cells from two non-asthmatic subjects and a human bronchial epithelial (HBE) cell line were challenged with either HDM or PBS as a control. The optimal dose of $25 \mu \mathrm{g} / \mathrm{ml}-\mathrm{HDM}$ was selected based on our prior analysis in the laboratory, which showed induction of inflammatory as well as robust ER stress responses in lung epithelial cells (data not shown). Seventy-two hours following repeated challenge, both subjects exhibited increases in phosphorylation of IRE1 (P-IRE), albeit to a greater extent in cells from subject 2, as well as increases in ER chaperone GRP78 (Bip), GRP94, and ERp57. ER stress transducer-ATF6 $\alpha$ and downstream transcriptional effector $\mathrm{CHOP}$ were also increased after HDM exposure (Figure 1A). With the exception of P-IRE, HBE cells responded in a similar manner with slight differences in kinetics between members of the ER stress responders (Figure 1A). As previously shown, physiological processes demanding a
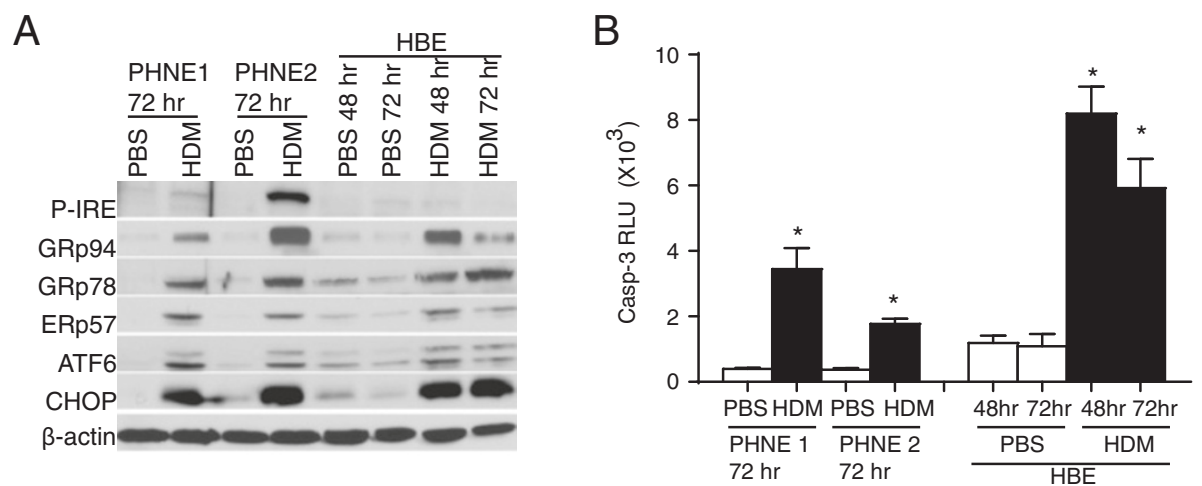

C
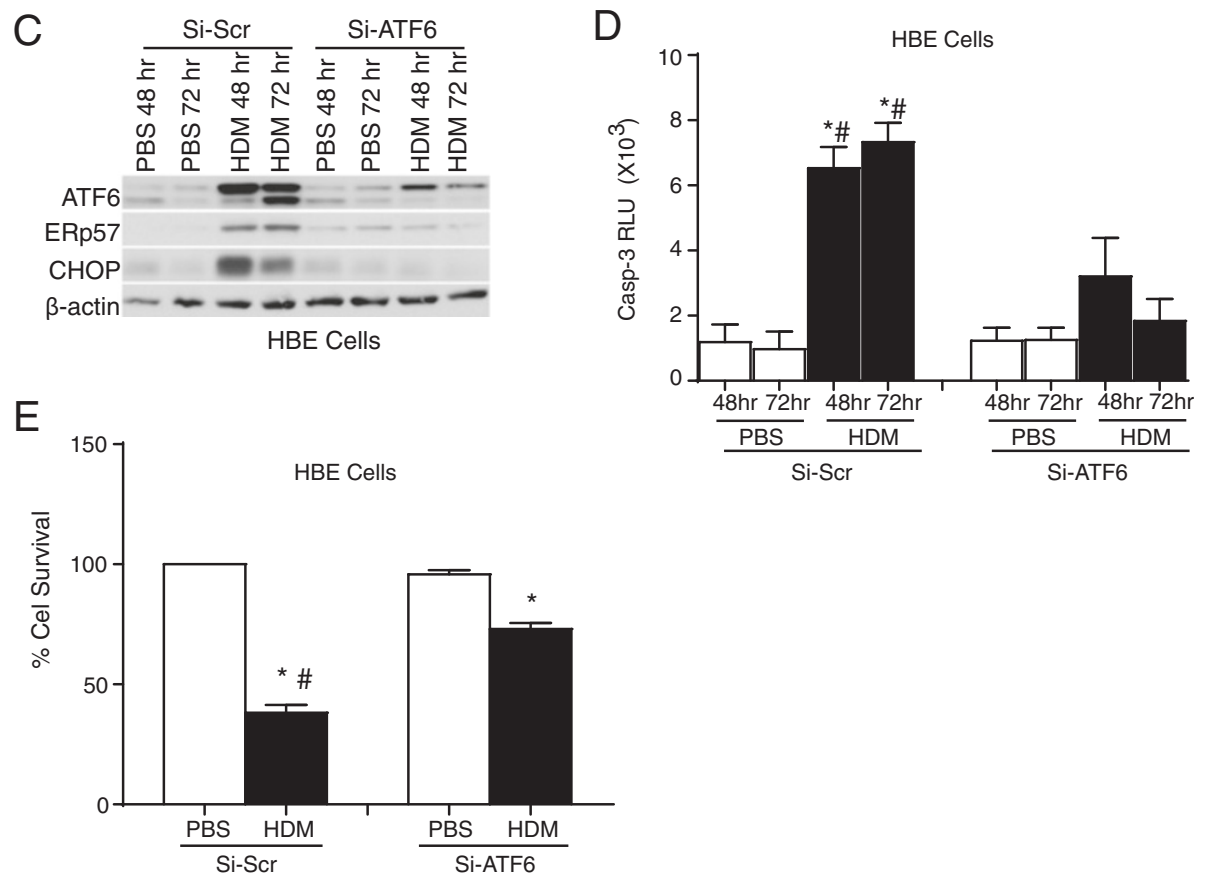

Figure 1 HDM induces ER stress and activation of caspase-3 in primary human nasal (PHNEs) and bronchial epithelial cells (HBE). PHNEs from two subjects and HBEs were treated with HDM for the indicated time. The cell lysates were subjected to western blot analysis to detect ER stress markers (A). Caspase-3 activity was measured using a luminescence assay (B). * indicates $p<0.05$ as compared to their PBS controls by ANOVA from 2 experiments in triplicate. HBE cells were transfected with siRNA for ATF6a or a non specific Scr sequence, challenged with HDM, and subjected to western blot analysis to detect ER stress markers (C). Caspase-3 activity was measured using a luminescence assay (D). Cell death was quantified using MTT assay (E). ${ }^{*}$ indicates $p<0.05$ as compared to their respective PBS controls. \# indicates $p<0.05$ as compared to their siRNA transfected HDM challenged samples (by ANOVA). 
high rate of protein synthesis and secretion may lead to unresolved ER stress resulting in apoptosis [14]. Accordingly, allergen exposure resulted in significant activation of caspase-3 at varying levels in both PHNE and HBE cells (Figure 1B).

During ER stress, activation of ATF6 $\alpha$ is known to specifically up regulate PDIs, chaperones, as well as CEBP homologous protein CHOP, and consequently, these events are known to lead to apoptosis [13,31]. To address the contribution of ATF $6 \alpha$ activation, chaperone induction, and downstream activation of apoptosis, HBE cells were transfected with either scrambled small interfering (si) RNA (Si-scr) or siRNA for ATF6 $\alpha$. Twenty-four hours following transfection, cells were stimulated with $25 \mu \mathrm{g}$ of HDM or PBS and harvested at 48 and $72 \mathrm{~h}$ after exposure. Knockdown of ATF $6 \alpha$ in HBE cells resulted in decreased activation of the $50 \mathrm{kD}$ fragment of ATF6 $\alpha$, CHOP, and ERp57 in whole cell lysates, indicating a requirement for ATF6 in HDM-driven expression of CHOP and ERp57 (Figure 1C). Following HDM administration, active caspase- 3 was increased and cell survival was decreased in scrambled siRNA transfected HBE cells. Knockdown of ATF $6 \alpha$ in HBE cells showed significant decrease in caspase-3 activity and an increase in cell survival (Figure 1D and E) in cell treated with HDM. These results indicate that allergen (HDM) exposure can induce ER stress, and in turn, lead to apoptosis in human lung epithelial cells.
HDM induces a robust ER stress response and apoptosis in mouse airway epithelial cells in vivo

To elicit allergic airways disease we challenged mice with a ubiquitous allergen-HDM, or Ovalbumin and compared the responses with mice treated with LPS (a model of acute lung injury and inflammation). Mice were initially sensitized and challenged via intranasal administration of HDM, LPS or low endotoxin OVA with $0.1 \mu \mathrm{g}$ of LPS (as an adjuvant) and were euthanized on day 21 [27] (Figure 2A). Results in Figure 2B and Additional file 1: Figure S1 demonstrates activation of ER stress in response to HDM or OVA/LPS in the whole lung, as evidenced by increases in phosphorylation of IRE1, as well as increased expression of GRP78, GRP94 and ERp57. ATF6 $\alpha$ and CHOP were also increased after HDM exposure as compared to controls. In contrast to our observation in the HDM model, ATF6 $\alpha$ did not appear to increase after OVA/LPS, but we observed a slight elevation in GRP94 and CHOP expression (Figure 2B and Additional file 1: Figure S1). Analysis of inflammatory cells showed a significant increase in eosinophils and lymphocytes in both models as compared to controls (Table 1). Macrophages were decreased in HDM challenged mice as compared to PBS controls, while in LPS and OVA/LPS challenged mice there was a significant increases in macrophages (Table 1). Immunofluorescence of HDM-instilled lungs indicated increased ERp57 as well as active caspase- 3 predominantly in the bronchiolar
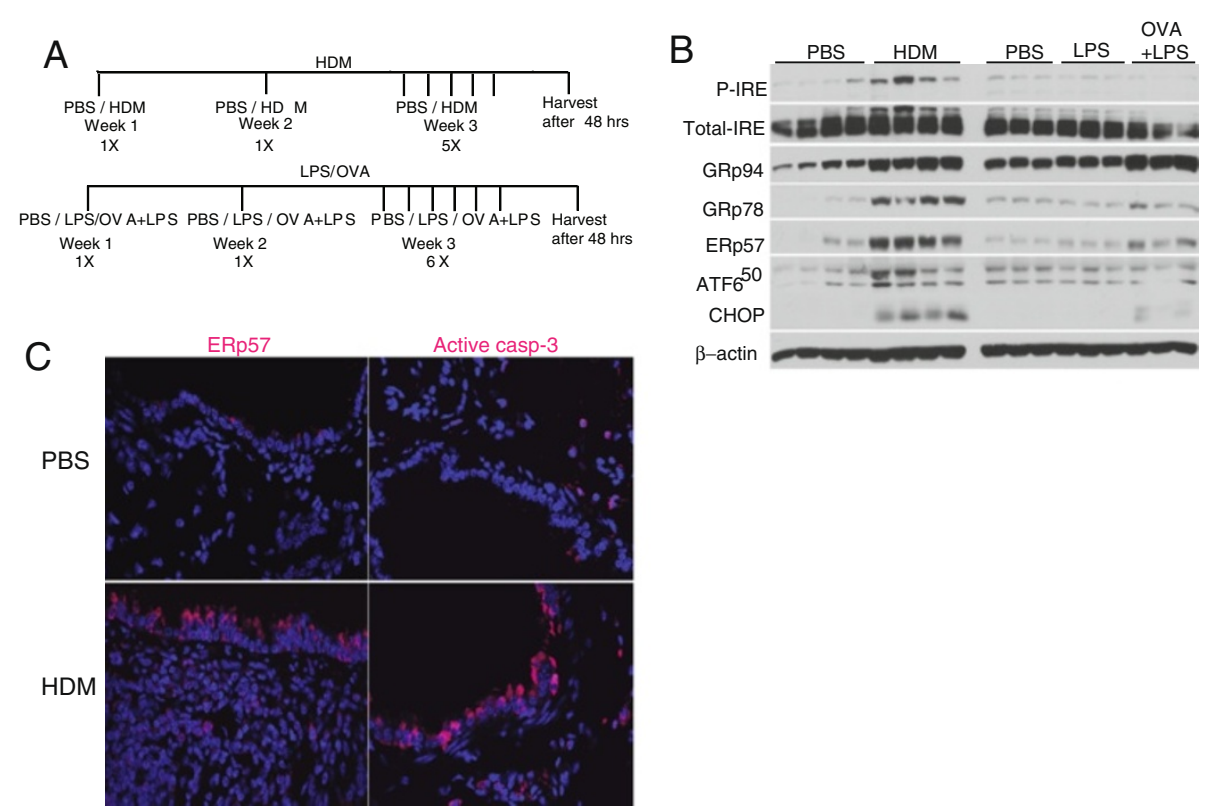

Figure 2 HDM induces ER stress and active caspase-3. Mice were challenged with PBS, HDM, LPS or Ovalbumin + LPS as depicted (A) Western blot analysis of whole lung lysates for ER stresses markers (B). Representative images showing up-regulation of ERp57 and active caspase-3 in the airway epithelium of HDM challenged mice $(n=4)(\mathbf{C})$. 


\begin{tabular}{|c|c|c|c|c|c|}
\hline \multicolumn{6}{|c|}{ BAL cell differentials } \\
\hline$\times 10^{3}$ & PBS & HDM & PBS & LPS & OVAL/LPS \\
\hline MACS & $43.6 \pm 5.0$ & $21.4 \pm 5.0^{*}$ & $27.2 \pm 4.9$ & $40.6 \pm 6.6^{*}$ & $100.5 \pm 16.4^{*} \#$ \\
\hline EOS & $0.7 \pm 0.4$ & $189.4 \pm 26.3^{*}$ & $0.0 \pm 0.0$ & $0.1 \pm 0.1$ & $51.2 \pm 10.3^{*} \#$ \\
\hline PMN & $1.3 \pm 1.2$ & $1.4 \pm 0.2$ & $0.2 \pm 0.0$ & $0.1 \pm 0.1$ & $21.5 \pm 6.0^{*} \#$ \\
\hline LYMPH & $0.7 \pm 0.3$ & $15.7 \pm 2.1$ & $1.6 \pm 0.6$ & $3.0 \pm 0.9$ & $29.8 \pm 7.1^{* \#}$ \\
\hline
\end{tabular}

*indicates $p<0.05$ as compared to their respective PBS controls.

\#indicates $p<0.05$ as compared to their respective LPS treated mice.

epithelium, as compared to controls (Figure 2C). Collectively these results demonstrate that HDM is a potent activator of ER stress in murine models of allergic airway disease, in comparison to Ovalbumin. Based on these results we continued our evaluations of the role of ER stress in allergic airways disease using the HDM model.

\section{Knockdown of ATF6a and ERp57 decreases CHOP, Bak oligomerization, and apoptosis in mice}

To evaluate the role of ATF6 $\alpha$ and ERp57 in HDMinduced allergic airways disease in vivo, mice were administered $10 \mathrm{mg} / \mathrm{kg}$ oropharyngeal scrambled siRNA (Si-scr) or siRNA targeting ERp57 and ATF6 $\alpha$. Subsequently, the mice were challenged via the intranasal administration with $50 \mu \mathrm{g}$ of HDM consecutively on days 15-19 and euthanized $72 \mathrm{~h}$ after final challenge (Figure 3A). As expected, protein expression of ERp57 and ATF6 $\alpha$ in the whole lung was decreased after repeated HDM exposure in mice that received siRNA for ERp57 and ATF6 $\alpha$ (Si-ERp57 + ATF6) compared to siRNA control samples (Si-scr). We also observed decreases in CHOP and GRP78 in HDM challenged mice treated with SiERp57 + ATF6 $\alpha$ as compared to Si-scr. The elevated expression of GRP94 was not altered following HDM challenge and treatment with Si-ERp57 + ATF6 $\alpha$ relative to Si-scr HDM groups (Figure 3B and Additional file 1: Figure S2), demonstrating that not all ER stress responders were altered by knockdown of ERp57 and ATF6 $\alpha$. ER stress-induced ERp57 is known to form disulfide (-S-S-) bridges in proapoptotic Bak [16]. Results in Figure 3C and Additional file 1: Figure S2 demonstrate that siRNA-mediated knockdown of ERp57 and ATF6 $\alpha$ resulted in significantly decreased -S-S- mediated oligomerization of Bak, manifested by decreases in the 75 and $50 \mathrm{kD}$ forms of Bak. Furthermore, we also observed that caspase-3 activity and Poly (ADP-ribose) Polymerase (PARP), a target for caspase- 3 cleavage during apoptosis, was significantly decreased in the whole lung lysates after ATF6 $\alpha$ and ERp57 knockdown following HDM challenge compared to Si-scr controls (Figure 3D and E). This indicates that knockdown of ATF6 $\alpha$ and
ERp57 results in significant decrease in HDM-induced, ER stress-mediated apoptotic cascade in the lung.

\section{Knockdown of ERp57 and ATF6a partially decreases airway inflammation and airway hyperresponsiveness (AHR)}

As expected, animals in the Si-scr or Si-ERp57 + ATF6 groups that were not exposed to HDM exhibited primarily macrophages in BALF. However, mice that received Si-scr and were challenged with HDM showed a marked influx of cells into the airways, characterized by increases in eosinophils, lymphocytes, and to a lesser extent, neutrophils. In contrast, knockdown of ERp57 and ATF6 $\alpha$ resulted in decreases in HDM-induced eosinophils and lymphocytes (Figure 4A, B, C, and D). As expected, we observed significant increases in IL-13 mRNA in HDM challenged mice as compared to PBS controls. Additionally, there was no significant increase in IFN $\gamma$ mRNA (Additional file 1: Figure S3), indicating that instillation of double stranded siRNA did not alter HDM-induced responses from Th2 to Th1. To address the functional effects of siRNA-mediated knockdown of ERp57 and ATF6 $\alpha$ in the airways, a forced oscillation technique was used to evaluate alterations in respiratory mechanics $[28,29]$ in response to HDM challenge. We did not observe any significant differences in central airway resistance $\left(R_{n}\right)$ at either the lowest or highest dose of methacholine in HDM-challenged siRNAtreated groups of mice, but we did observe significant increases in $R_{n}$ in mice that received Si-ERp57 + ATF6 $\alpha$ as compared to Si-scr, after HDM challenge (Figure 5A). In the peripheral airways, tissue resistance/dampening (G) and elastance/stiffness $(\mathrm{H})$ were significantly decreased in mice that received Si-ERp57 + ATF6 $\alpha$ as compared to $\mathrm{Si}$-scr, after HDM challenge (Figure $5 \mathrm{~B}$ and $\mathrm{C}$ ). Although our analysis revealed an increase in Muc5AC mRNA levels after HDM challenge, there were no significant differences in levels of Muc5AC mRNA or Periodic Acid Schiff (PAS) staining in HDM-challenged ERp57 + ATF6 $\alpha$-siRNA treated groups (data not shown).

\section{SiRNA mediated knockdown of ERp57 and ATF6a decreases airway fibrosis}

To examine the role of ATF6 $\alpha$ and ERp57 in airway remodeling, collagen deposition was evaluated following siRNA-administration and HDM exposure. Analysis of deposition of collagen by Masson's Trichrome in mice receiving HDM and Si-scr exhibited significant increases over PBS controls, whereas animals that were treated with HDM and received si-ERp57 + ATF6 $\alpha$ showed decreases in Masson's trichrome staining (Figure 6A) as compared to HDM treated, $\mathrm{Si}$-scr animals. Semi quantitative scoring for Masson's trichrome staining by three independent scientists blinded to the identity of the samples revealed significant decreases in HDM challenged si-ERp57+ 


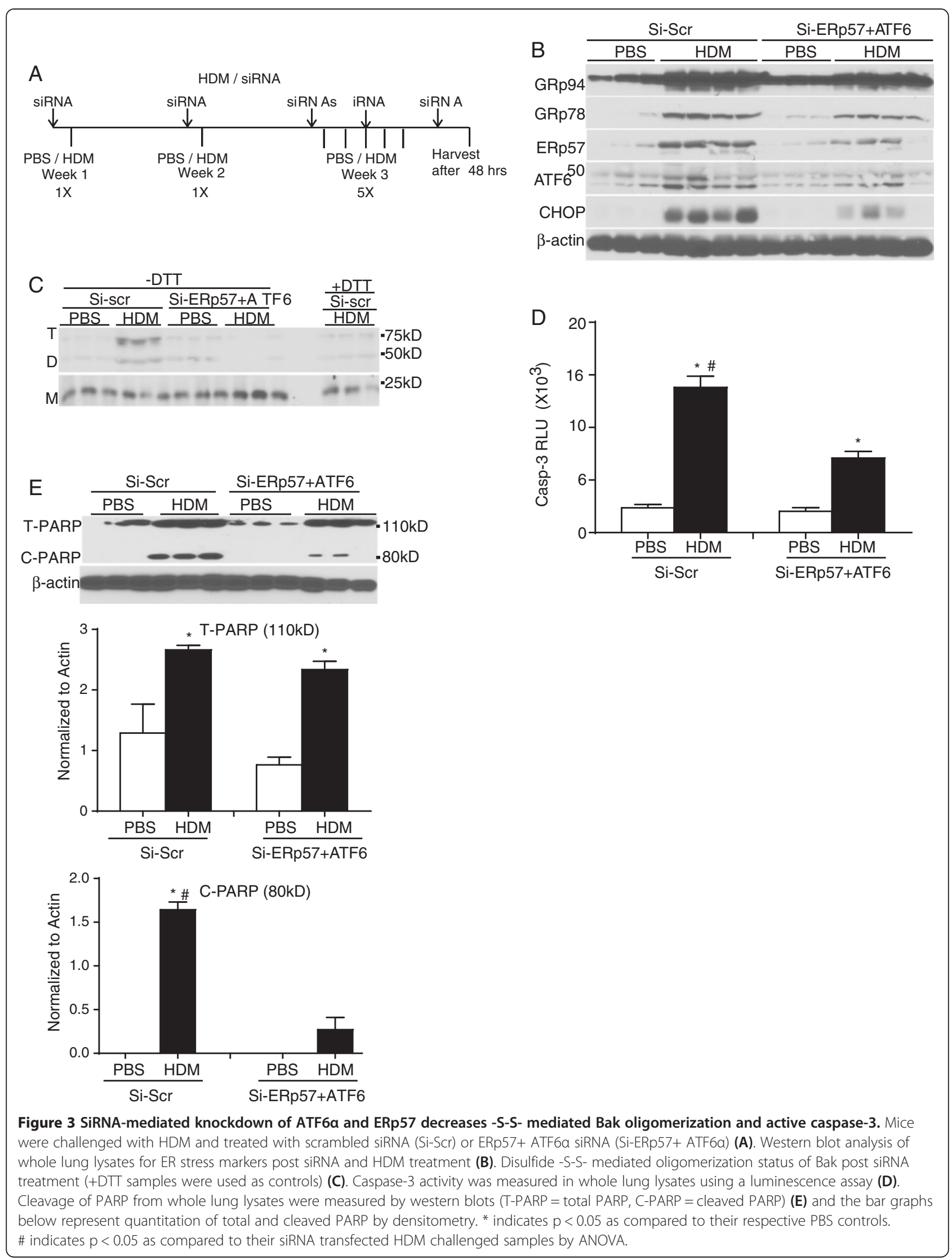



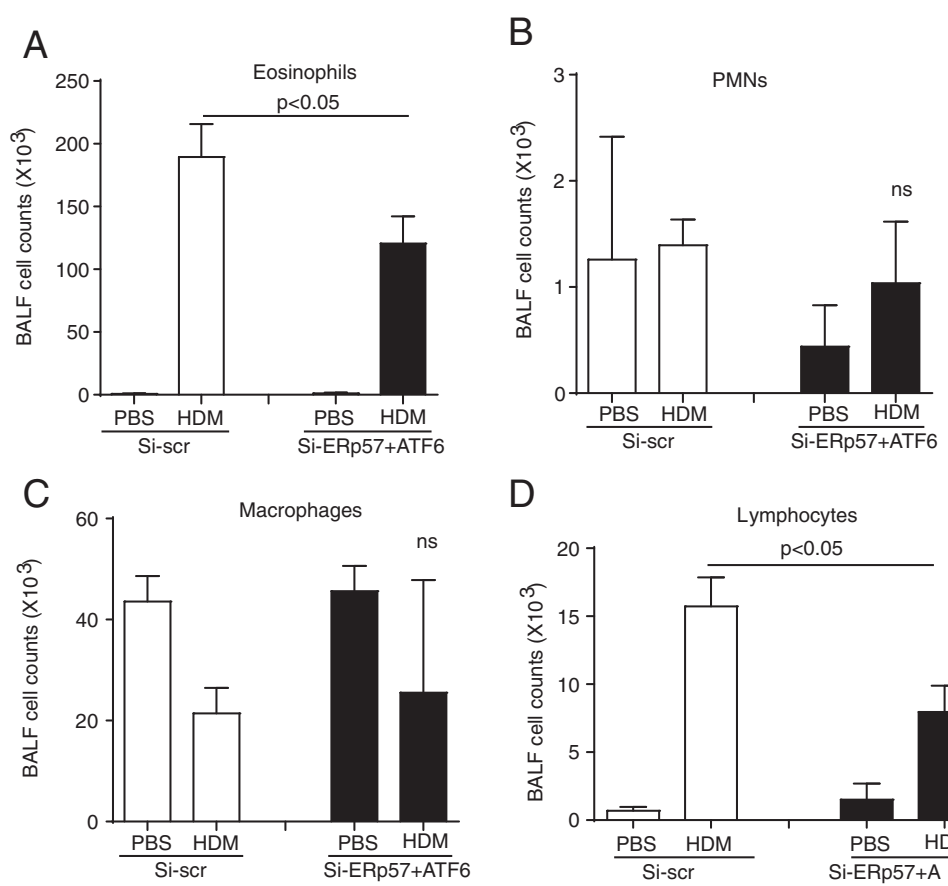

D

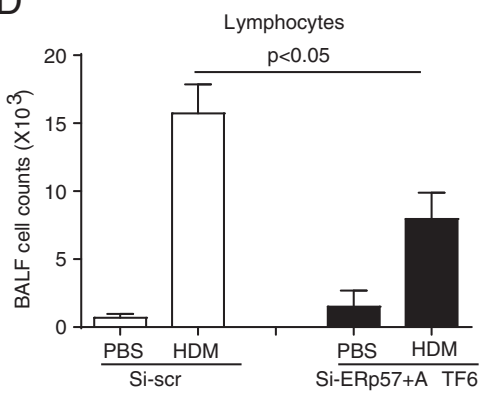

Figure 4 SiRNA-mediated knockdown of ATF6a and ERp57 partially decreases HDM-induced eosinophils and lymphocytes in BALF. Mice were challenged with HDM and treated with siRNA as depicted in Figure 3A. BALF fluid was collected from mice $(n=10 / \mathrm{group})$ and eosinophils (A), PMNs (B), macrophages (C) and lymphocytes (D) were counted using a hemocytometer. $p<0.05$ as measured by ANOVA, ns $=$ not significant.

ATF6 $\alpha$ treated mice (Figure 6B) over HDM Si-scr treated animals. Additionally, alpha-smooth muscle actin ( $\alpha \mathrm{SMA})$ was increased in the peribronchiolar region of HDM challenged mice treated with Si-scr (Figure 6C) as compared to HDM challenged si-ERp57 + ATF6 $\alpha$ treated mice. Western blot analysis of whole lung lysates also showed a significant increase in $\alpha$ SMA and Fibroblast Specific Protein (FSP-1) in HDM challenged mice treated with Si-scr (Figure 6D and Additional file 1: Figure S4). These increases were attenuated in mice challenged with HDM and treated with si-ERp57 + ATF6 $\alpha$ (Figure 6D and Additional file 1: Figure S4). Furthermore, we also observed an increase in total collagen content in whole lung lysates from HDM challenged mice treated with $\mathrm{Si}$-scr as compared to mice challenged with HDM and treated with si-ERp57 + ATF6 $\alpha$ (Figure 6E). Collectively these results indicate that ER stress mediators act to control allergen induced airway fibrosis in the lung.

\section{Discussion}

Perturbations in ER homeostasis can cause ER stress, and when unresolved, ER stress is known to activate cell death [32]. Recent reports suggest that phosphorylation of ER stress transducer IRE1 (P-IRE) and subsequent $\mathrm{X}$-box binding protein 1 (XBP-1) activation is required to induce mucus metaplasia in the lungs of mice challenged with ovalbumin $[17,18]$. Those reports did not address the implications of ER stress in other facets of asthma, such as epithelial apoptosis, airway hyperresponsiveness and fibrosis. In the current investigation we sought to determine the mechanism by which HDM, a common aeroallergen, induces multiple facets of human asthma in mice. Our results demonstrate induction of severe ER stress in human nasal and bronchial epithelial cells, as well as in mice after administration of HDM. Furthermore, we also found that HDM-induced ER stress is associated with airway epithelial cell death, hyperresponsiveness and subsequent airway fibrosis in mice.

In contrast to recent reports $[17,18]$, our studies with human epithelial cells demonstrated that HDM-mediated activation of IRE1 is not consistent in primary nasal or bronchial epithelial cells. We observed increased phosphorylation of IRE1 in HDM challenged mice as compared to ovalbumin, LPS or ovalbumin/LPS challenged mice. However, we did not observe any downstream XBP-1 activation as in other published reports $[17,18]$. Activation of PKR-like ER kinase (PERK), phosphorylation of eIF $2 \alpha$, or expression of ATF4, was also not observed. Instead, we showed robust activation of ATF6 $\alpha$ and caspase- 3 in human epithelial cells and believe that the differences in the activation of specific ER stress transducers may be due to the complex signaling pathways activated in the epithelium by HDM, compared to the antigen ovalbumin or TLR4 agonist, LPS [5,11]. Thus, 


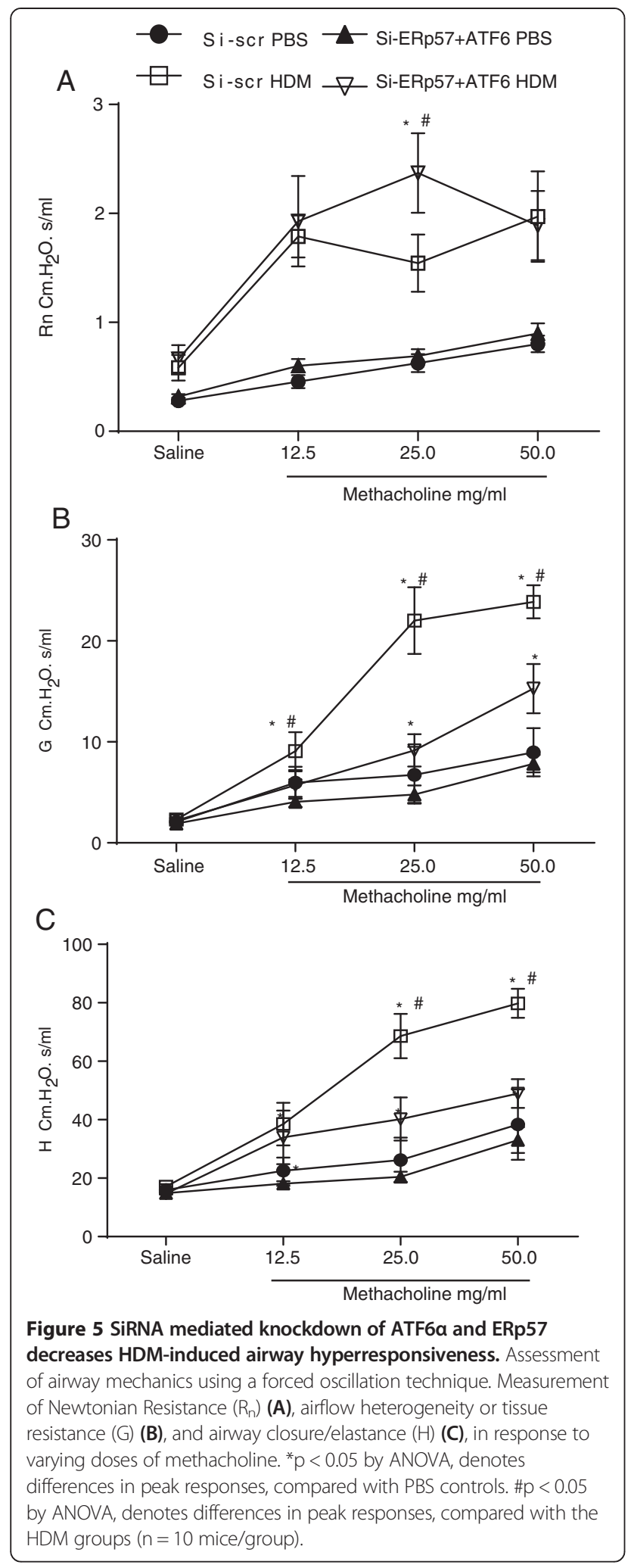

our results indicate a multifaceted mechanism of allergenspecific activation of ER stress mediators in mouse and human airway epithelial cells.
HDM challenge of human primary nasal and bronchial epithelial cells, as well as HDM exposure of mice, demonstrated consistent robust activation of chaperones, such as GRP94, GRP78 (Bip), ATF6 $6^{50 \mathrm{kDa}}$, a PDI-ERp57 and CHOP. Consistent with previously published data, our results demonstrate that chronic ER stress-mediated activation of ATF6 $\alpha$ led to increases in specific protein folding enzymes and subsequent activation of apoptotic executioner caspase-3 [14,33,34]. Interestingly, knockdown of ATF6 $\alpha$ in human bronchial epithelial cells, as well as ATF6 $\alpha$ and ERp57 in mice, resulted in decreased airway epithelial apoptosis as measured by activation of caspase-3. With the exception of GRP78 and CHOP [18], this up-regulation of specific ER stress and pro-apoptotic markers in allergic asthma has not yet been documented. It has been also suggested that chronic activation of ATF6 $\alpha$ can lead to the induction of CHOP and subsequent up regulation of proapototic Bak-mediated activation of caspases and apoptosis [16,35-37]. Accordingly, our results suggest that ATF6 $\alpha$ activation leads to up regulation of CHOP as well as ERp57, which is capable of inducing disulfide (-S-S-) mediated oligomerization of Bak and induction of intrinsic apoptosis [16].

Our in vitro results in human epithelial cells provide a clue that ATF6 $\alpha$ as a transcription factor is responsible for ERp57 expression. As shown by others, ATF6 $\alpha$ is also known to regulate inflammatory responses in models of other diseases $[38,39]$ alluding to the possibility that ATF6 $\alpha$ could be regulating HDM-induced inflammatory responses in the lung.

As reported in neuronal diseases, a severe ER stress response can lead to neuronal cell death $[16,40]$. Recent studies on ER stress-mediated neuronal apoptosis have also shown involvement of ERp57 in disulfide-mediated oligomerization of proapoptotic Bak [16]. Our work supports the notion that ER stress-induced ERp57 mediates Bak oligomerization and apoptosis of lung epithelial cells during HDM challenge. Furthermore, our results also showed that ERp57 mediated oligomerization of Bak and apoptosis was associated with airway fibrosis. Based on these results, and our data demonstrating ATF6dependent induction of ERp57, it is reasonable to speculate that ERp57 could be regulating apoptosis of epithelial cells downstream of ATF6 during HDM challenge. However, the role of ATF6 $\alpha$ and ERp57 in regulating airway hyperresponsiveness is unknown at this point. Therefore, in the future it would be interesting to conduct careful experiments in mice with lung epithelial cell specific ablation of ERp57 and/or ATF6 $\alpha$ to determine the role of these two proteins in allergic airway diseases.

ER stress transducers, such as ATF6 and CHOP, are known to play a prominent role in apoptosis of alveolar type II epithelial cells in fibrotic lung diseases, such as Idiopathic Pulmonary Fibrosis (IPF) [19,20] and Hermansky 


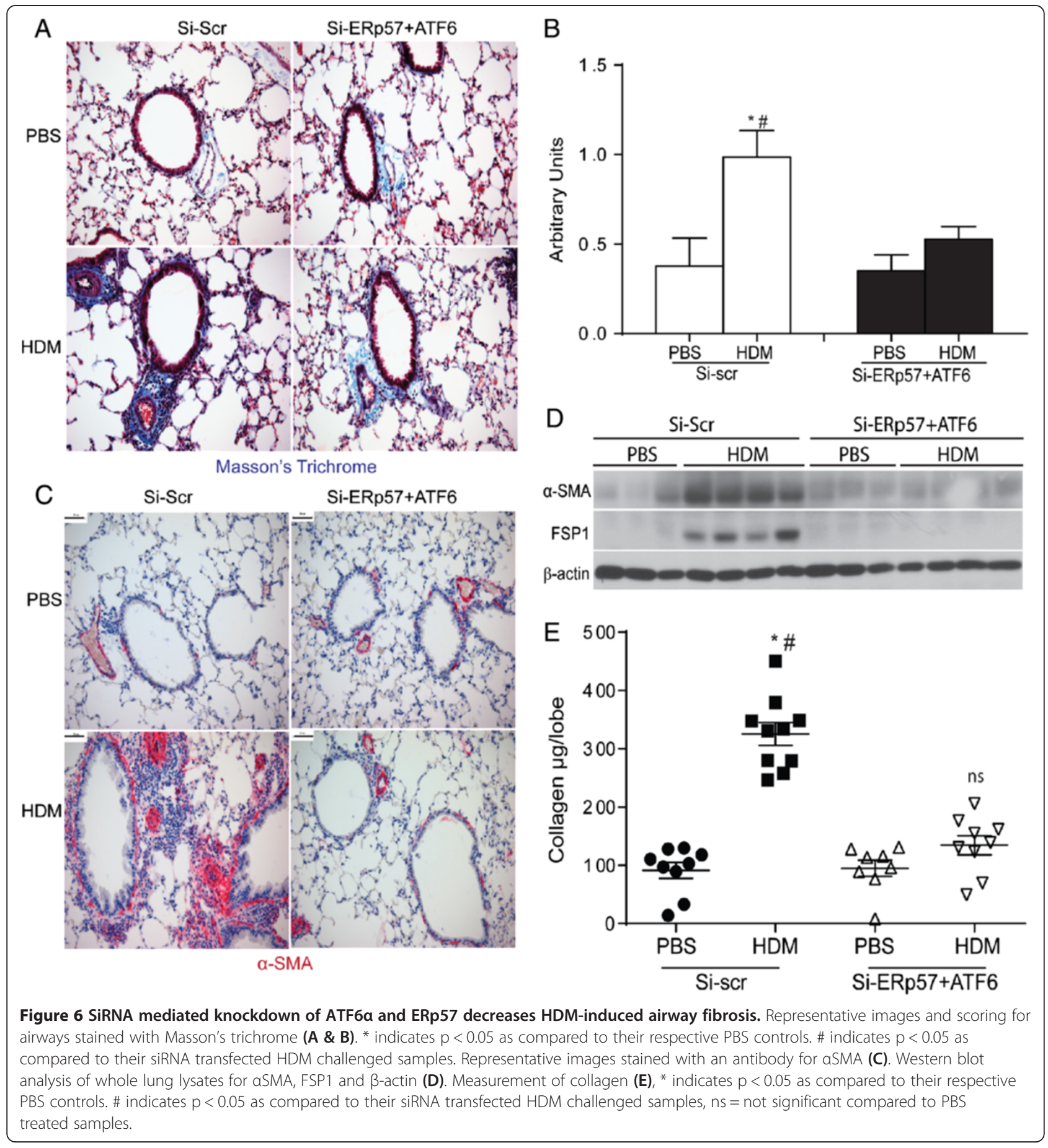

Pudlak Syndrome (HPS) [21]. Recent studies have suggested that asthmatics and HDM based mouse models of asthma develop sub-epithelial thickening marked by $\alpha$ SMA (smooth muscle hyperplasia) and increased collagen deposition, [2-4] resulting in peribronchiolar fibrosis. Accordingly results presented here show that HDM induces severe ER stress, leading to apoptosis of airway epithelial cells and subsequent fibrosis.
Complex allergens, such as HDM [5], may induce a physiological state that requires an increase in protein synthesis and folding (e.g. production of high levels of mucin, cytokines and surfactants) and create an imbalance in synthesis and capacity to fold, which in turn may increase misfolded proteins in the ER, eliciting the ER stress response and ultimately, apoptosis [15]. Furthermore, the allergen dependent chronic activation of ER stress and 
apoptosis can cause repeated injury to the airway epithelium. In fact, injured epithelium in human asthmatics as well as in mouse models up regulate profibrotic growth factors, stimulating proliferation of the underlying smooth muscle cells, and subsequently leading to the deposition of extracellular matrix proteins [41]. In our studies, we were unable to observe the up-regulation of various pro-fibrotic growth factors, perhaps as a consequence of the protracted time of in vivo analyses.

Eosinophilic inflammation is one of the hallmarks of allergic asthma [42]. In our study, we found that knocking down ATF6 $\alpha$ and ERp57 resulted in partial attenuation of eosinophilic influx and lymphocytes in the BALF of HDM-challenged mice, indicating that ER stress may play a role in HDM-induced inflammatory responses. Our results also show that ER stress and apoptosis are associated with another critical facet of asthma, airway hyperresponsiveness to methacholine. HDM-induced tissue resistance (G) and tissue stiffness $(\mathrm{H})$ were decreased in mice after knockdown of ATF6 $\alpha$ and ERp57. It is tempting to speculate that these changes in respiratory mechanics are due to altered permeability of the small airways in association with enhanced apoptosis of epithelial cells, which could perhaps allow increased access of methacholine to smooth muscle cells $[43,44]$. Interestingly we did not observe statistically significant differences in central airway resistance $(\mathrm{Rn})$ in HDM-challenged, Si-scr mice as compared to HDM-challenged, Si-ERp57 + ATF6 $\alpha$ mice. The mechanisms of uncoupling of $R_{n}$ in these models are yet to be determined.

\section{Conclusion}

Collectively, our work illuminates a previously unexplored mechanism for HDM-induced airway inflammation and fibrosis via ER stress and apoptosis of epithelial cells. We also show that knocking down ER stress transducers ATF6 $\alpha$ and ERp57 decreases HDM-induced apoptosis of airway epithelial cells, bronchiolar fibrosis, inflammation, and airway hyperresponsiveness.

\section{Additional file}

Additional file 1: Endoplasmic Reticulum Stress Mediates House Dust Mite-induced Airway Epithelial Apoptosis and Fibrosis.

\footnotetext{
Abbreviations

HDM: House Dust Mite; OVA: Ovalbumin; LPS: Lipopolysaccharide; UPR: Unfolded protein response; IRE: Inositol requiring enzyme; GRP78: Glucose regulated protein 78; ATF6: Activating transcription factor 6; ERp57: Endoplasmic reticulum protein 57; CHOP: C/EBP homologous protein; PDI: Protein disulfide isomerase.
}

\section{Competing interests}

The authors declare that they have no competing interests.

\section{Authors' contributions}

SMH, MEP and VA designed research. SMH, JET, JDN, KGL, DHG, ND, MA and VA conducted experiments. AED provided human epithelial cells and necessary reagents to grow human cells. CGI, MEP and AED provided help with data interpretation. SMH and VA wrote the paper. All authors read and approved the final manuscript.

\section{Acknowledgements}

We thank Dr. Yvonne Janssen-Heininger for critical review of the manuscript. We thank Kendall Black for help with human epithelial cell culture, and Dr. David Chapman for critical comments on measuring airway hyperresponsiveness and data interpretation. This project was supported by the American Thoracic Society (ATS) Unrestricted grant program, Parker B Francis Fellowship, NIH P30 RR 031158 (VLC-COBRE pilot investigation award), Department of Pathology and College of Medicine University of Vermont, internal grant program to VA, as well as by the UVM microscopy imaging facility, supported by NCRR 1S10RR019246.

\section{Author details}

${ }^{1}$ Department of Pathology, Vermont Lung Center University of Vermont College of Medicine, Burlington, VT 05405, USA. ²Department of Medicine, Vermont Lung Center University of Vermont College of Medicine, Burlington, VT 05405, USA

Received: 2 July 2013 Accepted: 17 December 2013

Published: 24 December 2013

\section{References}

1. Roche WR, Beasley R, Williams JH, Holgate ST: Subepithelial fibrosis in the bronchi of asthmatics. Lancet 1989, 1(8637):520-524.

2. Noble PB, Ansell TK, James AL, McFawn PK, Mitchell HW: Airway smooth muscle dynamics and hyperresponsiveness: in and outside the clinic. J Allergy (Cairo) 2012, 2012:157047.

3. James AL, Elliot JG, Jones RL, Carroll ML, Mauad T, Bai TR, Abramson MJ, McKay KO, Green FH: Airway smooth muscle hypertrophy and hyperplasia in asthma. Am J Respir Crit Care Med 2012, 185(10):1058-1064.

4. Johnson JR, Wiley RE, Fattouh R, Swirski FK, Gajewska BU, Coyle AJ, Gutierrez-Ramos JC, Ellis R, Inman MD, Jordana M: Continuous exposure to house dust mite elicits chronic airway inflammation and structural remodeling. Am J Respir Crit Care Med 2004, 169(3):378-385.

5. Gregory LG, Lloyd CM: Orchestrating house dust mite-associated allergy in the lung. Trends Immunol 2011, 32(9):402-411.

6. Nelson RP Jr, DiNicolo R, Fernandez-Caldas E, Seleznick MJ, Lockey RF, Good RA: Allergen-specific lgE levels and mite allergen exposure in children with acute asthma first seen in an emergency department and in nonasthmatic control subjects. J Allergy Clin Immunol 1996, 98(2):258-263.

7. Chapman MD, Pomes A, Breiteneder H, Ferreira F: Nomenclature and structural biology of allergens. J Allergy Clin Immunol 2007, 119(2):414-420.

8. Fahlbusch B, Koch A, Douwes J, Bischof W, Gehring U, Richter K, Wichmann $\mathrm{HE}$, Heinrich J: The effect of storage on allergen and microbial agent levels in frozen house dust. Allergy 2003, 58(2):150-153.

9. Topp R, Wimmer K, Fahlbusch B, Bischof W, Richter K, Wichmann HE Heinrich J: Repeated measurements of allergens and endotoxin in settled house dust over a time period of 6 years. Clin Exp Allergy 2003, 33(12):1659-1666.

10. Da Silva CA, Pochard P, Lee CG, Elias JA: Chitin particles are multifaceted immune adjuvants. Am J Respir Crit Care Med 2010, 182(12):1482-1491.

11. Ryu JH, Yoo JY, Kim MJ, Hwang SG, Ahn KC, Ryu JC, Choi MK, Joo JH, Kim $\mathrm{CH}$, Lee SN, et al: Distinct TLR-mediated pathways regulate house dust mite-induced allergic disease in the upper and lower airways. J Allergy Clin Immunol 2013, 131(2):549-561.

12. Lan RS, Stewart GA, Henry PJ: Role of protease-activated receptors in airway function: a target for therapeutic intervention? Pharmacol Ther 2002, 95(3):239-257.

13. Tabas I, Ron D: Integrating the mechanisms of apoptosis induced by endoplasmic reticulum stress. Nat Cell Biol 2011, 13(3):184-190.

14. Hetz $C$ : The unfolded protein response: controlling cell fate decisions under ER stress and beyond. Nat Rev Mol Cell Biol 2012, 13(2):89-102.

15. Zhang K, Kaufman RJ: From endoplasmic-reticulum stress to the inflammatory response. Nature 2008, 454(7203):455-462. 
16. Hoffstrom BG, Kaplan A, Letso R, Schmid RS, Turmel GJ, Lo DC, Stockwell BR: Inhibitors of protein disulfide isomerase suppress apoptosis induced by misfolded proteins. Nat Chem Biol 2010, 6(12):900-906.

17. Schroeder BW, Verhaeghe C, Park SW, Nguyenvu LT, Huang X, Zhen G, Erle DJ: AGR2 is induced in asthma and promotes allergen-induced mucin overproduction. Am J Respir Cell Mol Biol 2012, 47(2):178-185.

18. Martino MB, Jones $L$, Brighton $B$, Ehre $C$, Abdulah $L$, Davis CW, Ron D, O'Neal WK, Ribeiro CM: The ER stress transducer IRE1beta is required for airway epithelial mucin production. Mucosal Immunol 2013, 6(3):639-654.

19. Korfei M, Ruppert C, Mahavadi P, Henneke I, Markart P, Koch M, Lang G, Fink L, Bohle RM, Seeger W, et al: Epithelial endoplasmic reticulum stress and apoptosis in sporadic idiopathic pulmonary fibrosis. Am J Respir Crit Care Med 2008, 178(8):838-846.

20. Lawson WE, Cheng DS, Degryse AL, Tanjore H, Polosukhin W, Xu XC, Newcomb DC, Jones BR, Roldan J, Lane KB, et al: Endoplasmic reticulum stress enhances fibrotic remodeling in the lungs. Proc Natl Acad Sci U S A 2011, 108(26):10562-10567.

21. Mahavadi P, Korfei M, Henneke I, Liebisch G, Schmitz G, Gochuico BR, Markart P, Bellusci S, Seeger W, Ruppert C, et al: Epithelial stress and apoptosis underlie Hermansky-Pudlak syndrome-associated interstitial pneumonia. Am J Respir Crit Care Med 2010, 182(2):207-219.

22. Olson N, Greul AK, Hristova M, Bove PF, Kasahara DI, van der Vliet A: Nitric oxide and airway epithelial barrier function: regulation of tight junction proteins and epithelial permeability. Arch Biochem Biophys 2009, 484(2):205-213.

23. Wu R, Zhao YH, Chang MM: Growth and differentiation of conducting airway epithelial cells in culture. Eur Respir J 1997, 10(10):2398-2403.

24. Jaspers I, Ciencewicki JM, Zhang W, Brighton LE, Carson JL, Beck MA, Madden MC: Diesel exhaust enhances influenza virus infections in respiratory epithelial cells. Toxicol Sci 2005, 85(2):990-1002.

25. Anathy V, Aesif SW, Guala AS, Havermans M, Reynaert NL, Ho YS, Budd RC, Janssen-Heininger YM: Redox amplification of apoptosis by caspase-dependent cleavage of glutaredoxin 1 and S-glutathionylation of Fas. J Cell Biol 2009, 184(2):241-252.

26. Reynaert NL, van der Vliet A, Guala AS, McGovern T, Hristova M, Pantano C, Heintz NH, Heim J, Ho YS, Matthews DE, et al: Dynamic redox control of NF-kappaB through glutaredoxin-regulated S-glutathionylation of inhibitory kappaB kinase beta. Proc Natl Acad Sci U S A 2006 103(35):13086-13091.

27. Wilson RH, Whitehead GS, Nakano H, Free ME, Kolls JK, Cook DN: Allergic sensitization through the airway primes Th17-dependent neutrophilia and airway hyperresponsiveness. Am J Respir Crit Care Med 2009, 180(8):720-730.

28. Riesenfeld EP, Sullivan MJ, Thompson-Figueroa JA, Haverkamp HC, Lundblad LK, Bates JH, Irvin CG: Inhaled salmeterol and/or fluticasone alters structure/function in a murine model of allergic airways disease. Respir Res 2010, 11:22.

29. Pantano C, Ather JL, Alcorn JF, Poynter ME, Brown AL, Guala AS, Beuschel SL, Allen GB, Whittaker LA, Bevelander $M$, et al: Nuclear factor-kappaB activation in airway epithelium induces inflammation and hyperresponsiveness. Am J Respir Crit Care Med 2008, 177(9):959-969.

30. Poynter ME, Irvin CG, Janssen-Heininger YM: Rapid activation of nuclear factor-kappaB in airway epithelium in a murine model of allergic airway inflammation. Am J Pathol 2002, 160(4):1325-1334.

31. Ma Y, Hendershot LM: Delineation of a negative feedback regulatory loop that controls protein translation during endoplasmic reticulum stress. J Biol Chem 2003, 278(37):34864-34873.

32. Wang $S$, Kaufman $\mathrm{RJ}$ : The impact of the unfolded protein response on human disease. J Cell Biol 2012, 197(7):857-867.

33. Galindo I, Hernaez B, Munoz-Moreno R, Cuesta-Geijo MA, Dalmau-Mena I, Alonso C: The ATF6 branch of unfolded protein response and apoptosis are activated to promote African swine fever virus infection. Cell Death Dis 2012, 3:e341

34. Roberson EC, Tully JE, Guala AS, Reiss JN, Godburn KE, Pociask DA, Alcorn JF, Riches DW, Dienz O, Janssen-Heininger YM, et al: Influenza induces endoplasmic reticulum stress, caspase-12-dependent apoptosis, and c-Jun N-terminal kinase-mediated transforming growth factor-beta release in lung epithelial cells. Am J Respir Cell Mol Biol 2012 46(5):573-581.

35. Yao $S$, Zong $C$, Zhang $Y$, Sang $H$, Yang $M$, Jiao $P$, Fang $Y$, Yang $N$, Song $G$, Qin S: Activating transcription factor 6 mediates oxidized LDL-induced cholesterol accumulation and apoptosis in macrophages by up-regulating CHOP expression. J Atheroscler Thromb 2013, 20(1):94-107.

36. Fu HY, Okada K, Liao Y, Tsukamoto O, Isomura T, Asai M, Sawada T, Okuda $K$, Asano Y, Sanada S, et al: Ablation of C/EBP homologous protein attenuates endoplasmic reticulum-mediated apoptosis and cardiac dysfunction induced by pressure overload. Circulation 2010, 122(4):361-369.

37. McCullough KD, Martindale JL, Klotz LO, Aw TY, Holbrook NJ: Gadd153 sensitizes cells to endoplasmic reticulum stress by down-regulating $\mathrm{Bcl} 2$ and perturbing the cellular redox state. Mol Cell Biol 2001, 21(4):1249-1259.

38. Cao SS, Zimmermann EM, Chuang BM, Song B, Nwokoye A, Wilkinson JE, Eaton KA, Kaufman RJ: The unfolded protein response and chemical chaperones reduce protein misfolding and colitis in mice. Gastroenterology 2013, 144(5):989-1000. e1006.

39. Cao SS, Kaufman RJ: Unfolded protein response. Curr Biol 2012, 22(16):R622-R626

40. Ono $Y$, Tanaka H, Tsuruma $K$, Shimazawa M, Hara H: A sigma-1 receptor antagonist (NE-100) prevents tunicamycin-induced cell death via GRP78 induction in hippocampal cells. Biochem Biophys Res Commun 2013, 17(4):904-909.

41. Holgate ST, Roberts G, Arshad HS, Howarth PH, Davies DE: The role of the airway epithelium and its interaction with environmental factors in asthma pathogenesis. Proc Am Thorac Soc 2009, 6(8):655-659.

42. Amelink M, de Nijs SB, de Groot JC, van Tilburg PM, van Spiegel PI, Krouwels FH, Lutter $\mathrm{R}$, Zwinderman AH, Weersink EJ, Ten Brinke A, et al: Three phenotypes of adult-onset asthma. Allergy 2013, 68(5):674-680.

43. Bates JH, Cojocaru A, Haverkamp HC, Rinaldi LM, Irvin CG: The synergistic interactions of allergic lung inflammation and intratracheal cationic protein. Am J Respir Crit Care Med 2008, 177(3):261-268.

44. Poynter ME, Cloots R, van Woerkom T, Butnor KJ, Vacek P, Taatjes DJ, Irvin CG, Janssen-Heininger YM: NF-kappa B activation in airways modulates allergic inflammation but not hyperresponsiveness. J Immunol 2004, 173(11):7003-7009.

doi:10.1186/1465-9921-14-141

Cite this article as: Hoffman et al: Endoplasmic reticulum stress mediates house dust mite-induced airway epithelial apoptosis and fibrosis. Respiratory Research 2013 14:141.

\section{Submit your next manuscript to BioMed Central and take full advantage of:}

- Convenient online submission

- Thorough peer review

- No space constraints or color figure charges

- Immediate publication on acceptance

- Inclusion in PubMed, CAS, Scopus and Google Scholar

- Research which is freely available for redistribution 